Session 3686

\title{
Concurrent Innovation: The Impact of PRIDE's Collaborative Approach to Work Force Education and Retraining
}

\author{
Robert Bowman \\ The Shipyard College \\ Philadelphia Naval Business Center \\ Carole M. Mablekos, Ronald W. Smith \\ Department of Materials Engineering \\ Drexel University
}

\begin{abstract}
As an education and training consortium, the Partnership for Retraining and Innovations in Delivering Education (PRIDE) established over its first three years a highly productive mode for sharing resources and expertise. Instituted to provide assistance to workers affected by a military base conversion, this collaboration has had a wider impact on technology education, particularly in the development of a new cross-institutional curriculum that advances engineering and technical education by aligning it with real-life manufacturing activities and workplace skills. A clear indicator of PRIDE's success has been to strong desire of the partners, area economic development agencies, and city work force agencies for the consortium to continue. Work on future developments is underway, with a central focus on transportation technologies.
\end{abstract}

Introduction. Rapid, responsive, and agile work force education has become a crucial regional need, as industries now demand sophisticated work force skills. This demand is particularly significant in the Greater Philadelphia area, formerly a flourishing manufacturing center, now struggling to cope with increasing global competition and a serious decline in its industrial base. Many industries have either left the area or have curtailed their operations, citing both a poor business climate and a lack of skilled employees. Meanwhile, the increasing complexity of industrial operations demands that even technicians have associate's degrees or at least the equivalent of a two-year technical education. But while employers are increasing asking for employees with competency-based academic credentials, this crucial industrial region ranks last in terms of technology workers having some college level education. Thus, a dramatic improvement in access to education and training for the Greater Philadelphia technical work force will be essential is the region is to sustain itself as a manufacturing and industrial center.

This paper presents a preliminary assessment of the first three years of PRIDE and the Shipyard College, its shared facility for retraining displaced defense workers, along with a vision of the potential for sustained collaboration to have a positive impact on the future of this region.

Background on PRIDE and the Shipyard College. A college/university coalition devoted to manufacturing education and training, PRIDE consists of Drexel University, Camden County 
College, Delaware County Community College and Community College of Philadelphia, the U.S. Navy, and local Government. To establish the project, the consortium received a \$2million, 3-year grant from ARPA's Technology Reinvestment Project (TRP), with participating organizations providing a match of another \$2 million--for a total \$4-million effort. Over its first three years, this partnership has sought to lower the barriers to improved work force education, without sacrificing standards. The project's mission focused on educating and retraining displaced defense workers, and its immediate goals involved serving workers at the Philadelphia Naval Shipyard and Base. As the project progressed, the consortium integrated its immediate objective into a longer term goal: to assure that the region's highly skilled manufacturing labor base is maintained and updated through innovations in technology-based education and training.

Now in its final year of activity, the consortium has resolved to consolidate and build upon previous achievements. By continuing its collaboration in work force development with the Shipyard College as a nucleus of a coordinated effort, the consortium hopes to make a major difference in the manufacturing revitalization of this region, with attendant benefits to the nation as a whole being a natural outcome. The following sections describe three major areas of PRIDE's impact: (1) the successful conversion of naval base to business center, (2) the improvement of technology-focused education at the institutions themselves, and (3) addressing regional and national issues in work force education.

Helping Convert Naval Base to Business Center. The Shipyard College (SYC) was established at the Philadelphia Naval Shipyard and Base to deliver highly accessible and flexible on-site education assistance for Base workers and to administer the consortium's educational and training programs. An executive director and a staff of four administered the SYC programs, with efforts being supplemented by seven college academic advisors and an entrepreneurial counselor from the Council on Adult and Experiential Learning. Administrative and faculty teams from the four colleges dealt with other management and program issues, such as job placement, special programs, curriculum development, financial aid, and public relations. PRIDE worked closely with the Private Industry Council for tuition support, taking care to see that students were placed on career paths likely to lead to new employment. Students "clients" were counseled about their educational needs and interests while they organized their retraining programs in support of their career plans. These activities were augmented through the services of other agencies and organizations, such as the City of Philadelphia, the Philadelphia Industrial Development Corporation (PIDC), and the Department of Commerce.

In setting up the SYC academic program, the four PRIDE colleges could offer collectively what no single institution could offer by itself: a pool of over 4,000 faculty members who could offer a broad range of technology curricula and programs, ranging from the associate's degree through graduate levels. Over the first three years, more than fifty courses and training programs, selected according to student interest, were offered at the base through the SYC. Student evaluations showed that almost all courses were rated from good to excellent. If certain students wanted only short term training or some specially tailored program, the SYC could also respond readily. One very successful new program developed through the Shipyard College for those employees interested in starting their own businesses was the Entrepreneurial Training Program. This program, which provides built-in flexibility and mentoring, has been already recognized as a model program that can be replicated elsewhere as the need arises. Funded by the Private Industry Council with the support of the City of Philadelphia, PIDC, and Coleman Foundation, 
the program has been offered three times, with over twenty-four new business start-ups, most of which have stayed in business for over a year--an excellent record for new small businesses. To date, nearly 2000 displaced defense workers (out of a total of over 5000) took advantage of the many SYC services. Only preliminary surveys of actual job placement are currently being made, as many of these clients are still involved in their academic programs. Final surveys of employment success rates will take place in 1998, PRIDE's final year.

Shipyard College services have been extended to businesses and industries locating at the site of the former Naval Base, now being redeveloped under the auspices of the PIDC into the Philadelphia Naval Business Center (PNBC). The SYC is well poised to deliver "just-in-time" education and training and provide ready access to state-of-the-art training programs drawn from the collective curricula of three colleges and a university. Access to such programs, particularly as they are so readily adaptable to client needs, is already proving very helpful in drawing new tenants to the PNBC, which has set up a Small Business Incubator adjacent to the SYC to maximize client access to convenient training. Thus, by working closely with a major city and its economic development agencies through the SYC, the PRIDE institutions have able to make major strides in establishing a powerful and comprehensive business and industry training entity. The on-going redevelopment of the former base into an industrial park therefore promises to provide many attractive opportunities for continued collaboration.

Blending Theory and Practice in Curriculum Development. Work force education and training must teach not only technical "facts" but a broader "system" understanding, which is essential to improved productivity and performance. Curriculum development activities therefore need to be structured around need for technicians to be educated in more depth and for engineers to be educated in more breadth. Workers at all levels need to develop analytical, problem solving, and communication skills. The theoretical knowledge presented in engineering and technical curricula thus need to be continually re-aligned with real-life manufacturing activities. Also needed are industry-driven courses that include workplace skills enhancement, teamwork training, concurrency, horizontal project management. Finally, as current master technicians retire (an increasing phenomenon), investing in higher levels of training will be essential to assure that skilled technician mentors will be available for training future entry level workers.

Modularized Curriculum Offerings. PRIDE approached these needs by first undertaking a general evaluation of manufacturing-related content already developed at all four colleges. Courses with a significant degree of technology content were then placed in "modules" of three to seven related courses focused around a specific manufacturing skill, which could then be offered as "PRIDE Certificates." The consortium could offer a very broad spectrum manufacturing courses and laboratories drawn from their collective curricula. Appropriate courses were modularized into groups of three to six, under five technology focus areas: Automation, Advanced Composite Materials, Environmental and Remediation Technology, Telecommunications and Information Processing, and Biotechnology. Through the course module approach, students of all levels could use these modules as educational "milestones" that would provide manageable goals and facilitate progress along a student's career ladder. Students or workers who wanted just a specific manufacturing skill might need to take just one or two modules. Qualified students, of course, could eventually apply credit-bearing courses to appropriate degrees as either requirements or technical electives. The guiding principle was to make the curriculum as flexible as possible, thus providing reasonable options for students to move onto or off of different career-preparation paths. 
Innovative New Courses. To enrich their joint manufacturing-focused curriculum, PRIDE also sponsored the development of sixteen new industry-focused courses from associate to graduate level, some of which are cross-discipline, cross-institutional, and multi-level. For example, in an innovative course on optical and electronic device manufacturing that integrates real-world manufacturing activities into the learning experience, three groups of students acting as technicians, engineers, and researchers cooperated in teams that fabricated devices in a state-ofthe-art clean room laboratory. Working in a concurrent engineering paradigm, multi-level teams learned about optical/electronic device fabrication and operation, along with developing essential skills in group dynamics. A novel aspect of this course was that community college students were invited to take part as technicians. All levels of students expressed great enthusiasm for the outcomes of this course, even though it required more work. According to their final evaluations, one of the most appreciated benefits was that this course vividly revealed how collaboration can enhance skill acquisition and amplify individual knowledge and expertise.

Other innovative courses include a CAD/CAM series that brings modern and concurrent engineering concepts into the classroom. Each course has its own theme and emphasis: CAD/CAM in Concurrent Engineering; Knowledge-based Design and Flexible Manufacturing; and Concurrent Engineering: Design for Manufacturing. Another new course involves multilevels of students in the design, manufacture, and testing of high powered lasers of the type used in medicine, materials processing, optical communications, and research. In a new automation sequence, a TDC-3000 system donated to the PRIDE consortium by Honeywell, Inc. serves as the centerpiece three courses in hierarchical and distributed industrial control. The course was also designed for multiple student levels: for seniors and graduate students, it emphasizes control principles and controller configurations; for technicians-in-training and associate degree seeking students, it emphasizes the operation of DC systems.

The new PRIDE course have demonstrated that just as teamwork practices have been revolutionizing the manufacturing world, the collaborative work in the class and laboratory is powerful. Helping to establish strong cooperative links between industry and academia, courses that strongly link theory to practice can generate valuable benefits, particularly in that they provide the students with hands-on experimentation and with direct association with many key factory floor issues facing our industries today. The following is a list of the new and planned PRIDE manufacturing skills courses, all of which were designed to include innovative content and method and a close alignment--through hands-on student experiences--to real-world manufacturing: 


\section{Manufacturing of Composite Materials}

- Introduction to Enhanced Laboratory Experience in Composites Engineering

- Composite Materials Manufacturing, Science, and Technology Engineering

Manufacturing of Electro-Optic Devices

- Laser Device Manufacturing

- Optical and Electrical Materials Manufacturing

- Manufacturing of Optical Sensors and Systems with Applications

Industrial and Process Control

- Control Fundamentals Overview

- DES Formulation and Introduction to Industrial Process Control

- Process Control Projects

\section{Concurrent Engineering}

- $\mathrm{CAD} / \mathrm{CAM}$ in Concurrent Engineering

- Knowledge-based Design and Flexible Manufacturing

- Concurrent Engineering: Design for Manufacturing

Telecommunications and Information Technology

- Television, Satellite Communications and Fiber Optics

- Data Communications

- Analog Communication and Microwave Technology

- Introduction to Optics and Optical Wave Guides

- Fiber-Optic Applications

Working from Project to Established Technology Education and Training Center. The PRIDE partners plan to maintain their established mode for sharing resources and developing innovative work force education and training well into the future. They will continue to work together through the Shipyard College, and their approach will involve an effective blend of "hands-on" and "high-tech" that can be tailored to industry needs. For example, a new coordinated education and training initiative in transportation technologies is currently under development through the Shipyard College.

Transportation, a crucial industry for the Eastern Seaboard region as well as one with national and international impact as well, is "a natural fit" for PRIDE. Companies such as Allied Signal, 
Carrier/United Technologies Corporation, Advanced Transit Services, Metro Machine, River Associates, Terminal Freight, Conrail, Norfolk Southern, UPS and AMTRAK have already entered into discussions with the PRIDE partners, stressing the need to find efficient and accessible ways for transportation workers at all levels to improve skills and to earn professional credentials, stressing that rote learning is no longer sufficient, even for technicians and operators.

Transportation Training. These companies have expressed strong interest in the excellent possibilities for training through the Shipyard College. For the "hands-on" component of these programs, the PNBC provides a secure and spacious location for a large-scale transportation training, with its ample roadways and facilities for supporting hands-on training efforts. The site offers more than 1100 acres; 300 buildings with five million square feet of space; 52 miles of streets; a complete utility infrastructure; railheads, airport, highway and port facilities; and four miles of water-front property--so that the needs of every kind of transportation mode, whether rail, air, sea, over-the-road, and inter modal, can be included. Transportation training characteristically involves a widely distributed student body who could benefit from on-the-road training programs; therefore, these companies have opened discussions on how innovative "hightech" teaching methods, such as computer-based training, multi-media course support, and distance learning, could be applied. As an initial effort in this direction, PRIDE has a self-paced CD-ROM format for independent surface transportation operators, partially supported by the Coleman Foundation grant, already in development.

Transportation Education. Each institution had certain interests in transportation technologies, but PRIDE has amplified these interests and encouraged more development. Thus, the Community College of Philadelphia will complete its A.A.S. degree program in Railroad Operations and is currently working with other transportation companies, including United Parcel Service, the Philadelphia International Airport, the City of Philadelphia Streets Department, to develop tailored degree programs for their employees; Delaware County Community College has a partially developed A.A.S. degree program in Transport Refrigeration being supported by United Technologies. Camden County College is developing a program in Traffic and Transportation Management. The three colleges are also beginning a joint program for the operator and technicians in the trucking industry through the Shipyard College, where computer-based distance learning training will be a major component. In support of the career ladder concept, the three colleges will work with Drexel University toward "seamless" articulation to Drexel's upcoming "two plus two" degree: a Bachelor of Engineering Technology. Such flexible career path options along with improved on-the-job training would make it possible for an operator to progress to an entry level technician level, a technician could gradually work toward higher educational levels, and promising technical workers could proceed toward advanced technology, engineering, or science studies without starting over from the very beginning.

Despite a general agreement on the need for industry-driven education and training, employers and employees have yet to find consensus on how to provide and/or access the training. They do agree, however, on these major issues: more and better training, customizing to specific industry needs, and improved access to faculty, courses, and courseware so that training provides maximum benefits with minimum time off the job.

Conclusion. More than ever, today's rapidly changing manufacturing world depends on an 
educated and technically skilled work force, one which will require continuous learning just to keep pace. Lifelong education and training programs that increase needed skills will therefore become increasingly important to the region's and the nation's economic success.

PRIDE has had a unique opportunity to serve a community need while improving the region's manufacturing educational and retraining programs.

The project has successfully attained its initial goals: providing effective and flexible worker retraining to displaced defense workers and developing innovative technology curricula and programs. The special assets of a former defense facility have allowed PRIDE to maximize its impact, by providing a strong foundation from which new industrial enterprises can emerge, solid preparation for young people interested in manufacturing related careers, and skill-building opportunities for experienced workers. PRIDE, however, is not just another government program: rather it is a concept--that the career retraining needs of regional workers and employers must be a central concern and a key responsibility of the region's educational institutions, particularly in these times of shrinking educational funds but expanding needs of increasing numbers of non-traditional students in the midst of career changes. Through the Shipyard College, a responsive education and training center located in a prime industrial location ready for growth, this educational and training concept can be sustained, and the workforce education and economic development model developed by PRIDE will continue to have significant impact, regionally and even nationally.

Robert Bowman is the Executive Director of the Shipyard College. His industrial experience includes nine years in the transportation industry in manufacturing, sales, and leasing. He has served as Associate Director of the Arizona Commission on Post-Secondary Education and as Executive Director of the Pennsylvania Association of Universities of the State System of Higher Education. His E.Ed. is from Rutgers in 1979.

Carole Mablekos is Project Manager for the PRIDE Project. Her publications include an IEEE monograph on oral presentations techniques for engineers, andTechnical Writing for Chemists and Chemical Engineers (1988) for the American Chemical Society. She holds a M.A. from Virginia Polytechnic Institute and State University (VPI) and a Ph.D. from Purdue University.

Ronald W. Smith directs Drexel University's Center for Engineering Technology Education Center (CEnTEC), which included all technology related education and training partnerships for delivering new individual and corporate programs. In this position, Dr. Smith also leads the TRP/MET PRIDE program as Director. Dr. Smith also has over 14 years of experience in industry. His B.S. and M.S. degrees are from Northeastern University (1976) in Mechanical Engineering, and his Ph.D. degree is from Drexel (1985) in Materials Engineering. 